\title{
BRE INDEX FOR THE HONG KONG RESIDENTIAL PROPERTY MARKET
}

\author{
Eddie Chi Man HUI and Joe Tak Yun WONG \\ The Department of Building and Real Estate, The Hong Kong Polytechnic University, Hung Hom, Kowloon, \\ Hong Kong. \\ E-mail: bscmhui@polyu.edu.hk
}

Received 2 April 2004; accepted 14 June 2004

\begin{abstract}
This paper examines housing price trends and prediction, of homeowners and potential home buyers, and establishes an independent index (the BRE Index) based on longitudinal telephone surveys collected. The Index, first of this kind in Hong Kong, measures price expectations and benchmarks the level of housing actors' confidence in the residential market. This is the first paper delivered as part of a government-funded research project. It synthesizes the key findings of the first survey mounted from $17^{\text {th }}$ to $20^{\text {th }}$ December, 2003. The results show that confidence among housing actors has begun to grow since the property crash in late 1997 with the "overall" BRE Index standing at 564 (0-1000 range). In general, homeowners, people with higher educational level and higher income are optimistic about the market outlook. Residential property prices are expected to rise marginally in the short term. Statistically, there is no significant difference in housing price expectations between homeowners and non-owners. In their minds, economic condition is the most important factor affecting housing decisions. Apparently, the rising trends in the immediate past have been used to form expectations. The strength of the association between actual capital gains and forecast capital gains is moderately strong, and there appears co-movement between them. This leads us to believe that hope-led expectations increase the likelihood of sustaining price increases. The current market is largely driven by expectations. If households formed their expectations in a similar manner in other periods, there would be similar "positive hit" results, which might render the Index more powerful.
\end{abstract}

KEYWORDS: Property Price trends; BRE index; Market confidence; Hong Kong

\section{INTRODUCTION}

Since the Asian economic crisis in late 1997, deteriorating economic conditions have dramatically weakened consumer's confidence, particularly in the property market in Hong Kong. In 2003, property prices have sharply dropped by 65 percent from the 1997 peak. Hence, the market performance is of universal concern in the local community. Most previous studies have focused on inflationary expectations. There are also some consumer sentiment surveys in forecasting economic, social and political activities in Hong Kong. However, there are hardly any comprehensive surveys on housing price expectations and investor confidence. This project attempts to fill this important gap by building an independent property index to provide an objective basis for forecasting price movements and gauging the confidence level in the residential property market.

Most previous forecasts are based on the trend analysis of historic data, assuming the trend will continue in the future. Inflection points in price movements are missing until they are revealed as historical facts. The growth rate of real estate prices or the particular value of a real property in the past provides little help, if any, in predicting the pos- 
sible prices in the future. In the real world, people tend to change their price expectations when human, political and social situations changed. Price expectations of market participants and their attitudes towards the market are ignored in most previous studies. This project is unique in capturing the percentage change in longitudinal price expectations over time and the behavior of housing actors in residential property markets for developing timeseries indices. It is reasonably assumed that $\mathrm{BRE}$ indices are the most powerful and comprehensive indices ever established locally for the confidence prediction about residential properties in Hong Kong. The study is of high societal significance.

This paper is the first to be delivered as part of a government-funded research project entitled "BRE Index for the Hong Kong Residential Property Market." The Index adopts the name of the Department of Building and Real Estate (BRE) of the Hong Kong Polytechnic University (HKPolyU). The project has been undertaken by HKPolyU in collaboration with the Hong Kong Baptist University (HKBU) and the Texas A\&M University (TAMU) since June 2003. Its objectives are three-fold:

(a) To explore changes in price expectations and confidence of housing consumers over time in the performance of the local residential property market;

(b) To establish time-series BRE Indices for different groups of homeowners and non-owners in Hong Kong; and

(c) To develop trends of housing demand, decisions and preferences of homeowners and potential homebuyers.

This paper synthesizes the key findings of the first full-scale survey mounted during the period from $17^{\text {th }}$ to $20^{\text {th }}$ December 2003 . It provides tentative interpretations and conjectures for housing consumers' investment consideration, perception of current and future housing prices, housing decisions, and factors affecting their willingness to buy a real property in Hong Kong or elsewhere. The BRE Index is developed from each survey.
Following this introduction, Section 2 discusses the literature on price expectations, followed by the survey methodology in Section 3 . Section 4 contains a summary of the findings with interpretations and conjectures. Section 5 concludes the survey.

\section{LITERATURE REVIEW}

Expectations are indirect and unobservable, yet they are influential in the property market. Expectations are "the action or action of looking forward: anticipation," and "the state of looking forward: the mental attitude of one who anticipates" (Webster's Third New International Dictionary, p. 799).

Farmers' decision of how much to plant largely depends on the expected price of the crops that can be harvested in the future. The higher the expected price, the more they will plant, and vice versa. Similarly, in the real estate sector, the expected rental growth and house price appreciation are central to housing decisions. As long as people expect an increase in property prices, their behaviors will generate more demand, thereby pushing up property values, wages and production costs, initiating a cycle of price-expectation adjustment. Establishing price expectations helps understand market dynamics, and also improves the forecasting of possible price movements.

Muth's (1961) rational expectations hypothesis is that the subjective expectations of an economic variable are, such as future housing price, on average, equal to the expected value of the future housing prices given all the publicly available information. Put it simply, the assumption means that, on average, people's subjective expectations are correct. A number of studies have demonstrated that price expectations play a crucial role in the formation of house prices. In particular, Harris (1989) asserted that expectations of future appreciation are important determinants of house sale prices. The results also provide evidence that expectations remain influential even in peri- 
ods of declining and moderate real prices. Phillips (1985) and McDonald (1985) concluded that expected nominal appreciation in house values, estimated as an extrapolation of past price increases, may bid up current house prices independent of expected rents. A step further, Krashinsky and Milne (1987) argued that housing demand responds not only to current prices but also price expectations.

Most economists rely on the definition of "weak" market efficiency that future prices cannot be predicted on the basis of past price trends. Historic prices are, therefore, of no value in forecasting future prices. This leads to a concept of a "random walk," whereby asset price changes follow a random pattern and excess returns cannot be predicted. However, high house price volatility in Hong Kong over the past years actually led to excess investment profit. Research provides evidence that real estate markets often violate the random walk and rational expectations hypothesis (Ott, et al., 2000). The empirical test of Clayton (1996) rejected the joint null hypothesis of rational expectations, suggesting price may deviate temporarily from its fundamental value in real estate price cycles. Hamilton and Schwab (1985), Case and Shiller (1989, 1990), and Mankiw and Weil (1989) supported that house price movements are positively correlated with historic capital gains in the short run. Information on real estate fundamentals and past price increases can be employed to predict future returns. Further, strongest expectations are formed by being adaptive to price change (Turnovsky, 1970; Diamond, 1980; Hamilton and Schwab, 1985; Tse and Webb, 2001). These findings are inconsistent with rational (forward looking) expectations or semistrong market efficiency.

If price expectations were based on the extrapolation of past price increases (backward looking or adaptive expectations), it would lead to speculative enthusiasm or "bubble". The plausible explanation is that the previous high rate of price appreciation is non-rationally expected to continue into the future. Stiglitz
(1990) argued that the bubble exists if "the reason that the price is high today is only because investor believes that the selling price will be higher tomorrow - when 'fundamental' factors do not seem to justify such a price." If this is the case, an increase in property price is simply the outcome of self-fulfilling expectations - the Pygmalion Effect. More precisely, people predict price movements based on past trends, and excess profits could be earned by investors. It indeed happened in Hong Kong in the early 1990s. But that came to an end when the "bubble" burst during the Asian economic crisis of 1997.

\section{SURVEY METHODOLOGY}

\section{Interview Method}

The investigative methodology relies largely on longitudinal telephone surveys mounted every three months, in March, June, September and December. It is known that questionnaires are useful in collecting specific facts about individual behaviors. The coverage of samples is as wide as 98 percent of the households in Hong Kong with a residential telephone. Interviews are conducted by 20 independent and trained university students at respondents' convenience, usually at night on weekdays, under close supervision. Telephone interviews are conducted mainly in Cantonese.

The project was first piloted in November 2003, and the first major survey was smoothly conducted in December 2003. This interview method will be followed in future waves of surveys. The Computer-Assisted Telephone Interviewing (CATI) software is used in conducting surveys. CATI offers the benefits of automatic dials, reduced data cleaning, instant data updating, automatic data recording, and more importantly, prevention of man-made errors.

\section{Questionnaire Design}

The questionnaire is designed to probe the patterns of changes in housing price expectations of market participants over a certain period of time. The direction and magnitude of 
casual relations between price prediction and past price movements and economic variables are established. BRE Indices are set up, based on the results of each survey. The validity of the Index is improved by asking a number of questions related to the concept of price expectations and investor confidence.

Respondents are asked about their views on current and future residential property prices, investment consideration and sentiment, rational fundamental factors affecting their home purchase decisions and housing preferences $^{1}$. Demographic data of the respondents are also collected to find out if there is any difference in views between different population segments. The questions are simple and straightforward, and worded in everyday Chinese. Each telephone interview takes an average of five minutes to complete. As an incentive to participate, we offer to send survey results upon request, and post the results on HKPolyU's web site.

The questions are virtually identical, with consistent wording. Interviewees are required to answer the same set of questions in each round and at the very same time to minimize errors to which surveys are subject to. This also permits comparisons over time as well as across groups of respondents. Differences in answers are assessed to be the alterations in respondents' opinions and behaviors instead of differences in the wording and order of questions, economic conditions or demographic trend. Only inter- and intra-individual differences in answers between rounds of survey can be attributed to changes in mass psychology, buying behavior, investor confidence and expectations, economic conditions or demographic trends through time as well as across different cohort subjects. Survey questions, wording and ordering will remain the same in future longitudinal surveys. If sub-indices are to

\footnotetext{
${ }^{1}$ It should be noted that the questions are not equally weighed for the computation of the BRE Index. More emphasis would be put on questions related to price expectations (Q9-10).
}

be extended in the future, covered exclusively for "professional" or "amateur" cohorts, there would be changes in the order and wording of the survey questions.

\section{Target Population}

The target respondents of the survey are the non-expert populace in the local residential property sector. There are two kinds of samples: a sample of homeowners, and a sample of potential homebuyers in Hong Kong, both aged 18 or above.

Respondents are specifically "branched" into six groups and sampled in each survey, as follows:

1. Group A - Homeowner (HO)

a. Group A1 - Homeowner in the market considering another purchase

b. Group A2 - Homeowner and conditional purchaser

c. Group A3 - Homeowner and non-buyer

2. Group B - Non-homeowner (NHO)

a. Group B1 - Non-homeowner in the market considering new purchase

b. Group B2 - Non-homeowner and conditional purchaser

c. Group B3 - Non-homeowner and nonbuyer

\section{Sampling Procedures}

Hong Kong residential telephone directories are used as the sampling frame. Computergenerated random sampling procedures are employed to ensure a random selection of homeowners and potential homebuyers. First, telephone numbers are drawn from three residential telephone directories of the New Territories, Kowloon and Hong Kong and Islands regions. Second, from these "number seeds" another set of numbers are generated by changing the last four digits randomly to include the unlisted or new numbers. Finally, the CATI system chooses the respondents randomly for interviews. Those who are unable to be contacted to conduct the interview in the first instance would be called back five more times in order to complete the interview. 


\section{Sample Size}

About 12,000 contact numbers are made. Based on trial study and the first full-scale survey, at least 900 successful interviews will be targeted for each round of the survey in the future.

\section{Rating Scale}

A random sample of respondents is required to choose from various choices representing a range of possible and mutually exclusive responses. There are also some open-ended questions, which aim to solicit more detailed information from respondents. In most questions, a Likert Five-point Scale is employed to measure respondents' attitudes and confidence of the local residential property market. In questions regarding price expectations, respondents are asked to think of the price change in percentage terms of their housing units over the preceding three months, and to forecast their house prices in the 3-month, 1-year and 3-year horizons.

\section{Index Computation}

The conceptual basis of confidence in forming BRE Indices is developed mainly from the experience of the Texas Real Estate Confidence Index (TRECI) established by TAMU. In developing BRE Indices, similar to the TRECI, positive confidence scores are assigned to "favorable" responses; and negative scores to "unfavorable" ones. Unlike TRECI, there is a wider range of scores for computing $\mathrm{BRE}$ Indices. Higher scores are given to higher level of confidence, and lower scores to lower confidence, as truly reflected in their answers. There are different ranges of scores for different questions, and the maximum range is from -4 to +4 .

A specific index is produced for a particular "Group" of respondents and an "Overall" index for all respondents. The specific index is derived from the non-equal weighted average of scores assigned to answers, over a number of "core" questions answered by each "Group" of respondents; and an "Overall" index by all respondents. This weighted averaging process enhances the reliability of the indices, reducing the impact of erratic answers.

$\mathrm{BRE}$ indices range from 0 (no confidence at all) to 1,000 (complete confidence). A BRE Index of 500 is considered neutral, less than 500 is negative, and more than 500 is positive. The closer the Index is to zero, the more the negative market outlook; and the closer it is to 1,000 , the more the positive outlook.

\section{SUMMARY OF FINDINGS}

This section presents the key findings of the first survey. Survey questions and responses are available at www.bre.polyu.edu.hk/research/bre_index/. Here are the highlights of the findings:

\section{Sample and Response Rate}

A total of 11,271 dials, out of 15,500 contact numbers randomly selected, were made and 3,515 target respondents were contacted with 810 interviews successfully completed.

Out of the 810 samples, 380 (47 percent) were homeowners (HOs) and 430 (53 percent) were non-homeowners (NHOs). About 70 percent of $\mathrm{HOs}$ lived in private residential flats while 48 percent of NHOs lived in public rental estates. Overall, 52 percent of respondents lived in private residential flats and 48 percent in public housing estates. This distribution is consistent with the actual population.

The overall response rate on the survey was 23.04 percent and the margin of sample error was +/- 3.1 percent at the 95 percent confidence level.

\section{BRE Indices}

The "Overall" BRE Index established from the first survey for the fourth quarter of 2003 was considered slightly positive at 564 . It was up eight points from the pilot survey conducted in November 2003. Individual BRE Indices for $\mathrm{HO}$ and NHO groups stood at 579 and 556, respectively. Table 1 below shows individual "Group" Indices and the "Overall" Index. 
Table 1. Summary of BRE Indices

\begin{tabular}{llll}
\hline \multirow{2}{*}{ Groups of Respondents } & N & BRE Index & \\
\cline { 3 - 4 } & & Individual & Overall \\
\hline A1 - Homeowner, considering purchase & 74 & 591.42 & \\
A2 - Homeowner and conditional purchaser & 87 & 579.16 & \\
A3 - Homeowner and non-buyer & 219 & N/A & 579.46 \\
\hline Homeowner & 380 & & \\
\hline B1 - Non-homeowner, considering purchase & 85 & 555.67 & \\
B2 - Non-homeowner and conditional purchaser & 95 & 534.92 & 555.88 \\
B3 - Non-homeowner and non-buyer & 250 & N/A & $\mathbf{5 6 3 . 9 8}$ \\
\hline$\quad$ Non-homeowner & 430 & & \\
\hline Overall & $\mathbf{8 1 0}$ & & \\
\hline
\end{tabular}

Since it is the first time that BRE indices are established, no comparison can be made with other similar indices previously built. In light of the recent increase in the number of property transactions, decrease in the number of negative asset loans, improved unemployment situation and various government initiatives, the Indices revealing the increasing confidence are not unrealistic.

\section{Housing Price Expectations}

A narrow majority (about 53 percent) of HOs and some 35 percent to 39 percent of NHOs believed that housing prices would rise in the short to medium term (three months to one year), with 34 percent of HOs and 27 percent of NHOs expecting, on average, a rise in the long term (three years). Note nearly half (48 percent) of HOs and slightly over half (54 percent) of NHOs had no idea about the price trend in the 3-year horizon (Table 2).

The difficulties in forecasting in the long term are mainly due to economic uncertainties, such as the government's attempt to balance the budget currently in deficit. As expected, HOs, in general, tended to be more optimistic than NHOs about the fortune of the real estate and the short-term market outlook.

Turning to HOs' and NHOs' projected price changes in the three forecast horizons, some 64 percent and 43 percent of HOs (51 percent and 30 percent of NHOs) forecasted that there would only be a small increase ranging from 1 percent to 5 percent in three months and one year, respectively. Only $4 \%$ of HOs and $17 \%$ of NHOs expected a decline in property prices of $0-5 \%$ in three months, as seen from Table 3.

Accordingly, HOs seemed to be more confident in the short-run market performance than NHOs. In the long term, however, more NHOs expected an increase of over 20 percent than their counterparts. Furthermore, nearly all respondents did not expect a price fall of more than 11 percent in the short term, nor any de-

Table 2. Expected Price Trend, by Group

\begin{tabular}{|c|c|c|c|c|c|c|c|c|c|c|c|c|}
\hline \multirow{3}{*}{ Price trend } & \multicolumn{6}{|c|}{ Groups A1 \& A2 } & \multicolumn{6}{|c|}{ Groups B1 \& B2 } \\
\hline & \multicolumn{2}{|c|}{ 3-month } & \multicolumn{2}{|c|}{ 1-year } & \multicolumn{2}{|c|}{ 3-year } & \multicolumn{2}{|c|}{ 3-month } & \multicolumn{2}{|c|}{ 1-year } & \multicolumn{2}{|c|}{ 3-year } \\
\hline & $\mathrm{N}$ & $\%$ & $\mathrm{~N}$ & $\%$ & $\mathrm{~N}$ & $\%$ & $\mathrm{~N}$ & $\%$ & $\mathrm{~N}$ & $\%$ & $\mathrm{~N}$ & $\%$ \\
\hline Rise & 72 & 51.8 & 74 & 53.3 & 47 & 33.8 & 54 & 34.8 & 61 & 39.4 & 42 & 27.1 \\
\hline Fall & 3 & 2.2 & 11 & 7.9 & 5 & 3.6 & 17 & 11.0 & 16 & 10.3 & 13 & 8.4 \\
\hline Stay the same & 40 & 28.7 & 23 & 16.5 & 21 & 15.1 & 40 & 25.8 & 25 & 16.1 & 16 & 10.3 \\
\hline Don't know & 24 & 17.3 & 31 & 22.3 & 66 & 47.5 & 44 & 28.4 & 53 & 34.2 & 84 & 54.2 \\
\hline Total & 139 & 100 & 139 & 100 & 139 & 100 & 155 & 100 & 155 & 100 & 155 & 100 \\
\hline
\end{tabular}


clines in the long run. All this suggests that confidence among housing actors have begun to grow, supporting the claim that there are real signs of recovery since the 1997 property crash.

Overall, the average expected housing price increase is $5.31 \%, 8.56 \%$ and $13.16 \%$ in the 3 month, 1-year and 3-year forecast horizons, respectively. The maximum expected price increase is $20 \%, 50 \%$ and $80 \%$ in the same three periods, respectively. A summary of statistics of price changes by homeowner and non-ho-

Table 3. Expected Price Changes in Percentage, by Group

\begin{tabular}{|c|c|c|c|c|c|c|c|c|c|c|c|c|}
\hline \multirow{3}{*}{ Change magnitude } & \multicolumn{6}{|c|}{ Groups A1 \& A2 } & \multicolumn{6}{|c|}{ Groups B1 \& B2 } \\
\hline & \multicolumn{2}{|c|}{ 3-month } & \multicolumn{2}{|c|}{ 1-year } & \multicolumn{2}{|c|}{ 3-year } & \multicolumn{2}{|c|}{ 3-month } & \multicolumn{2}{|c|}{ 1-year } & \multicolumn{2}{|c|}{ 3-year } \\
\hline & $\mathrm{N}$ & $\%$ & $\mathrm{~N}$ & $\%$ & $\mathrm{~N}$ & $\%$ & $\mathrm{~N}$ & $\%$ & $\mathrm{~N}$ & $\%$ & $\mathrm{~N}$ & $\%$ \\
\hline Above $+20 \%$ & 0 & 0 & 0 & 0 & 1 & 1.9 & 0 & 0 & 3 & 3.8 & 6 & 10.9 \\
\hline$+11 \%$ to $+20 \%$ & 5 & 6.7 & 11 & 13.1 & 15 & 28.3 & 6 & 8.5 & 13 & 16.9 & 15 & 27.3 \\
\hline$+6 \%$ to $+10 \%$ & 17 & 22.7 & 31 & 36.9 & 27 & 50.9 & 12 & 16.9 & 28 & 36.4 & 23 & 41.8 \\
\hline$+1 \%$ to $+5 \%$ & 48 & 64.0 & 36 & 42.8 & 9 & 17.0 & 36 & 50.7 & 23 & 29.9 & 8 & 14.5 \\
\hline$-1 \%$ to $-5 \%$ & 3 & 4.0 & 3 & 3.6 & 0 & 0 & 12 & 16.9 & 6 & 7.8 & 0 & 0 \\
\hline$-6 \%$ to $-10 \%$ & 1 & 1.3 & 1 & 1.2 & 0 & 0 & 4 & 5.6 & 2 & 2.6 & 0 & 0 \\
\hline$-11 \%$ to $-20 \%$ & 0 & 0 & 0 & 0 & 0 & 0 & 0 & 0 & 0 & 0 & 0 & 0 \\
\hline Above $-20 \%$ & 0 & 0 & 1 & 1.2 & 0 & 0 & 0 & 0 & 0 & 0 & 0 & 0 \\
\hline Don't know & 1 & 1.3 & 1 & 1.2 & 1 & 1.9 & 1 & 1.4 & 2 & 2.6 & 3 & 5.5 \\
\hline Total & 75 & 100 & 84 & 100 & 53 & 100 & 71 & 100 & 77 & 100 & 55 & 100 \\
\hline
\end{tabular}

Table 4. Summary of Statistics of Price Changes (a) Homeowner

\begin{tabular}{llllllll}
\hline & \multicolumn{2}{l}{ \% of Price Increase } & & \multicolumn{2}{c}{ \% of Price Decrease } & \multicolumn{2}{c}{$+/-$} \\
\hline & 3-Month & 1-Year & 3-Year & 3-Month & 1-Year & 3-Year & Prev 3 M \\
\hline Mean & 5.02 & 7.08 & 12.19 & -6.26 & 1.54 & 9.00 & 3.41 \\
Median & 4.00 & 8.00 & 10.00 & -5.00 & 3.00 & 10.00 & 5.00 \\
Mode & 2.00 & 10.00 & 10.00 & -5.00 & 5.00 & 10.00 & 5.00 \\
Std. Dev. & 3.77 & 7.91 & 10.88 & 2.50 & 6.49 & 2.23 & 7.59 \\
Minimum & 1.00 & -50 & 1.00 & -10.00 & -10.00 & 5.00 & -30 \\
Maximum & 20.00 & 20 & 80.00 & -5.00 & 10.00 & 10.00 & 15.00 \\
\hline Total & 70 & 72 & 47 & 4 & 11 & 5 & 86 \\
\hline
\end{tabular}

(b) Non-homeowner

\begin{tabular}{llllllll}
\hline & \multicolumn{2}{l}{ \% of Price Increase } & & \multicolumn{2}{c}{ \% of Price Decrease } & \multicolumn{2}{c}{$+/-$} \\
\hline & 3-Month & 1-Year & 3-Year & 3-Month & 1-Year & 3-Year & Prev 3 M \\
\hline Mean & 5.70 & 10.35 & 14.3 & -4.64 & 2.69 & 10.75 & 2.91 \\
Median & 4.00 & 10.00 & 11.00 & -5.00 & 1.00 & 10.00 & 5.00 \\
Mode & 2.00 & 10.00 & 10.00 & -5.00 & -5.00 & 10.00 & 5.00 \\
Std. Dev. & 4.59 & 7.74 & 9.17 & 3.52 & 9.33 & 6.77 & 7.75 \\
Minimum & 1.00 & 3.00 & 5.00 & -10.00 & -10.00 & 4.00 & -15.00 \\
Maximum & 20.00 & 50.00 & 50.00 & 5.00 & 20.00 & 30.00 & 20.00 \\
\hline Total & 53 & 59 & 40 & 17 & 16 & 12 & 61 \\
\hline
\end{tabular}


meowner groups is presented in Table 4. The last column of Table 4, indicating the past price movements reported by respondents, is shown for comparison. This will be discussed later under the section entitled "Forecast of Price Movements".

The results of independent T-tests show that, statistically, there is no significant difference in the percentage change in housing prices in the three forecast horizons between homeowners and non-owners, except for pricerise expectations in the 1-year period.

The cross-tabulation analysis shows that, in general, more people, under the age of 40 , tended to expect a price rise than those over 40. People with higher educational levels (matriculated and above) were more optimistic than less educated ones. Higher income groups (monthly family income of $\operatorname{HK} \$ 20,000$ and above) were more optimistic than lower income groups.

\section{Housing Consideration}

Forty-seven percent of HOs said that they thought the market price was "about right". In contrast, 42 percent NHOs thought that it was "somewhat too high" and 13 percent of NHOs felt that it was "extremely high".

Most respondents, in particular the NHO Group (83\%), thought of their purchase as for self-use; whereas for the HO Group, the figure was 63 percent. This indicates that home purchase in essence was not for investment or speculative purposes during the survey period.
Actually, the NHOs had very little incentive (3 percent) to own a real asset for investment purpose. The investment rating is not encouraging: some 36 percent of HOs (22 percent of NHOs) rated property purchase as a "good" or "very good investment". In the meantime, 27 percent of HOs (37 percent of NHOs) considered it a "bad" or "very bad investment".

As shown in Table 5, there seems to be no imminent need to buy a property in Hong Kong or elsewhere. Only a mere 5 percent of both HOs and NHOs planned to buy within three to six months. About 22 percent of HOs and 23 percent of NHOs wished to buy in one to three years. But over two-thirds of HOs and NHOs had no idea whatsoever of when to buy at all. The unwillingness to buy real property may be contributed to HOs' negative equity problems and NHOs' perceived high price and low family income. Note 27 percent of HOs had negative equity problems and 50.1 percent of NHOs had a family income of less than HK $\$ 20,000$ per month. Clearly, they perceived a great deal of risk and uncertainty when the economy was weak, hence no housing decisions would likely be made. There are some evidence that the market has just been revitalized, yet the weak propensity to buy is very clear.

The popular impression is that the best strategy in a sluggish market is to keep holding their money-losing investments to avoid being regretful. Note also that as many Hong Kong people saw their property prices depreciated sharply after the property crash in 1997,

Table 5. Timing to Buy a Real Property

\begin{tabular}{|c|c|c|c|c|c|c|c|c|c|c|}
\hline \multirow{3}{*}{ Timing } & \multicolumn{4}{|c|}{ Group A } & \multicolumn{4}{|c|}{ Group B } & \multicolumn{2}{|c|}{ Total } \\
\hline & \multirow{2}{*}{ A1 } & \multirow{2}{*}{$\mathrm{A} 2$} & \multicolumn{2}{|c|}{ Total } & \multirow{2}{*}{ B1 } & \multirow{2}{*}{ B2 } & \multicolumn{2}{|c|}{ Total } & \multirow{2}{*}{$\mathrm{N}$} & \multirow{2}{*}{$\%$} \\
\hline & & & $\mathrm{N}$ & $\%$ & & & $\mathrm{~N}$ & $\%$ & & \\
\hline Within 3 months & 4 & 1 & 5 & 3.1 & 3 & 1 & 4 & 2.2 & 9 & 2.6 \\
\hline Within 6 months & 3 & 0 & 3 & 1.9 & 5 & 1 & 6 & 3.3 & 9 & 2.6 \\
\hline Within 1 year & 13 & 4 & 17 & 10.6 & 9 & 2 & 11 & 6.1 & 28 & 8.2 \\
\hline Within 3 years & 9 & 9 & 18 & 11.2 & 21 & 12 & 33 & 18.4 & 51 & 15.0 \\
\hline Don't know & 45 & 73 & 118 & 73.2 & 47 & 79 & 126 & 70.0 & 244 & 71.6 \\
\hline Total & 74 & 87 & 161 & 100 & 85 & 95 & 180 & 100 & 341 & 100 \\
\hline
\end{tabular}


most of them decided to wait until they get their projected return from a property. To them waiting may pay off in the sluggish market.

From the cross-tabulation analysis, one striking result is that 26 percent of "wealthy" respondents, who earned an average monthly family income of HK\$30,000 and above, were unwilling to buy in the next three months, although they expected a rise in property prices. Apparently, these potential investors factored the economic uncertainty, which might lead to possible capital losses, in making their investment decisions. In short, non-home purchase groups tend to skew towards the high-income HOs and the low-income NHOs.

A popular belief in Hong Kong is that properties are always a safe investment, so long as one holds that long enough. If homeowners were not able to sell their house partly due to the negative equity problem, ultimately they would decide not to buy another house nor would they lower the selling price. The reluctance in cutting the asking price gives an impression to market participants that prices would not fall. That impression heightens the feeling of regret if one cuts the price. On the one hand, higher income homeowners are hesitant to invest; on the other hand, lower income non-owners with financial difficulties cannot afford a new house, which aggravates the problem of stagnation.

\section{Housing Preferences}

Table 6 is a summary of existing and preferred flat size of the respondents. The data shows that slightly more than half (52 percent) of HOs were living in smaller Type B flats (430 sq. ft. to 752 sq. ft.) and 28 percent in Type C (753 sq. ft. to 1,075 sq. ft.) when the interviews were conducted. HOs expressed greater interest, in general, in purchasing flats of Type C (40 percent) than that of Type B (32 percent). Similarly, 36 percent of NHOs lived in Type A (429 sq. ft. and below) and 45 percent dwelled in Type B flats. Fifty four percent of NHOs preferred Type B flats and 32 percent of those preferred Type $\mathrm{C}$ flats.

As discussed previously, the purpose of purchase for self-use was considered by most respondents. The results suggest that respondents inclined to improve their living environment by moving to larger flats. The responses leave a general impression that more HOs (26 percent) were willing to purchase larger (Type D - 1,076 sq. ft. to 1,720 sq. ft.) or luxurious flats (Type E - over 1,720 sq. ft.) than those NHOs (10 percent). As expected, it is due to their better financial conditions.

\section{Factors affecting Housing Decisions}

Numerous economic variables were cited as key factors. Family income was the most important factor affecting respondents' decision to buy real property. As shown in Table 7, an overwhelming 87 percent of HOs and 93 percent of NHOs said that it was either "important" or "very important", followed by local economic conditions considered by 78 percent of HOs and 83 percent of NHOs.

Table 6. Existing and Preferred Flat Sizes

\begin{tabular}{|c|c|c|c|c|c|c|c|c|}
\hline \multirow{3}{*}{ Flat Sizes } & \multicolumn{4}{|c|}{ Groups A1 \& A2 } & \multicolumn{4}{|c|}{ Groups B1 \& B2 } \\
\hline & \multicolumn{2}{|c|}{ Existing } & \multicolumn{2}{|c|}{ Preferred } & \multicolumn{2}{|c|}{ Existing } & \multicolumn{2}{|c|}{ Preferred } \\
\hline & $\mathrm{N}$ & $\%$ & $\mathrm{~N}$ & $\%$ & $\mathrm{~N}$ & $\%$ & $\mathrm{~N}$ & $\%$ \\
\hline A: Up to 429 sq. $\mathrm{ft}$ & 9 & 5.6 & 4 & 2.4 & 65 & 36.1 & 10 & 5.5 \\
\hline B: $430-752$ sq. ft. & 84 & 52.1 & 51 & 31.7 & 81 & 45.0 & 97 & 53.9 \\
\hline C: $753-1,075$ sq. ft. & 45 & 28.0 & 64 & 39.8 & 30 & 16.7 & 57 & 31.7 \\
\hline D: $1,076-1,720$ sq. ft. & 17 & 10.6 & 33 & 20.5 & 4 & 2.2 & 9 & 5.0 \\
\hline E: Over 1,720 sq. ft. & 6 & 3.7 & 9 & 5.6 & 0 & 0 & 7 & 3.9 \\
\hline Total & 161 & 100 & 161 & 100 & 180 & 100 & 180 & 100 \\
\hline
\end{tabular}


Table 7. Factors affecting Housing Decisions

\begin{tabular}{|c|c|c|c|c|c|c|c|c|c|c|c|c|c|c|}
\hline \multirow{3}{*}{ Importance } & \multicolumn{14}{|c|}{ Group A } \\
\hline & \multicolumn{2}{|c|}{ Income } & \multicolumn{2}{|c|}{ Econ } & \multicolumn{2}{|c|}{ Int. rate } & \multicolumn{2}{|c|}{ Location } & \multicolumn{2}{|c|}{ Rental } & \multicolumn{2}{|c|}{ Developer } & \multicolumn{2}{|c|}{ Queue } \\
\hline & $\mathrm{N}$ & $\%$ & $\mathrm{~N}$ & $\%$ & $\mathrm{~N}$ & $\%$ & $\mathrm{~N}$ & $\%$ & $\mathrm{~N}$ & $\%$ & $\mathrm{~N}$ & $\%$ & $\mathrm{~N}$ & $\%$ \\
\hline Very important & 103 & 64.0 & 48 & 29.8 & 38 & 23.6 & 24 & 14.9 & 10 & 6.2 & 6 & 3.7 & 4 & 2.5 \\
\hline Important & 37 & 23.0 & 78 & 48.4 & 72 & 44.7 & 90 & 55.9 & 55 & 34.2 & 78 & 48.5 & 22 & 13.6 \\
\hline Neutral & 11 & 6.8 & 19 & 11.8 & 24 & 14.9 & 27 & 16.8 & 31 & 19.2 & 30 & 18.6 & 19 & 11.8 \\
\hline Not important & 9 & 5.6 & 12 & 7.5 & 26 & 16.2 & 19 & 11.8 & 52 & 32.3 & 38 & 23.6 & 69 & 42.9 \\
\hline Not at all important & 1 & 0.6 & 4 & 2.5 & 1 & 0.6 & 1 & 0.6 & 12 & 7.5 & 8 & 5.0 & 47 & 29.2 \\
\hline Don't know & 0 & 0 & 0 & 0 & 0 & 0 & 0 & 0 & 1 & 0.6 & 1 & 0.6 & 0 & 0 \\
\hline \multirow[t]{2}{*}{ Total } & 161 & 100 & 161 & 100 & 161 & 100 & 161 & 100 & 161 & 100 & 161 & 100 & 161 & 100 \\
\hline & \multicolumn{14}{|c|}{ Group B } \\
\hline \multirow[t]{2}{*}{ Importance } & \multicolumn{2}{|c|}{ Income } & \multicolumn{2}{|c|}{ Econ } & \multicolumn{2}{|c|}{ Int. rate } & \multicolumn{2}{|c|}{ Location } & \multicolumn{2}{|c|}{ Rental } & \multicolumn{2}{|c|}{ Developer } & \multicolumn{2}{|c|}{ Queue } \\
\hline & $\mathrm{N}$ & $\%$ & $\mathrm{~N}$ & $\%$ & $\mathrm{~N}$ & $\%$ & $\mathrm{~N}$ & $\%$ & $\mathrm{~N}$ & $\%$ & $\mathrm{~N}$ & $\%$ & $\mathrm{~N}$ & $\%$ \\
\hline Very important & 126 & 70.0 & 67 & 37.2 & 37 & 20.6 & 25 & 13.9 & 17 & 9.4 & 19 & 10.6 & 0 & 0 \\
\hline Important & 42 & 23.3 & 83 & 46.0 & 86 & 47.7 & 103 & 57.2 & 77 & 42.8 & 64 & 35.6 & 33 & 18.3 \\
\hline Neutral & 8 & 4.4 & 14 & 7.8 & 32 & 17.8 & 30 & 16.7 & 33 & 18.3 & 33 & 18.3 & 18 & 10.0 \\
\hline Not important & 2 & 1.1 & 14 & 7.8 & 20 & 11.1 & 17 & 9.4 & 34 & 18.9 & 47 & 26.1 & 82 & 45.5 \\
\hline Not at all important & 1 & 0.6 & 1 & 0.6 & 3 & 1.7 & 3 & 1.7 & 16 & 8.9 & 15 & 8.3 & 46 & 25.6 \\
\hline Don't know & 1 & 0.6 & 1 & 0.6 & 2 & 1.1 & 2 & 1.1 & 3 & 1.7 & 2 & 1.1 & 1 & 0.6 \\
\hline Total & 180 & 100 & 180 & 100 & 180 & 100 & 180 & 100 & 180 & 100 & 180 & 100 & 180 & 100 \\
\hline
\end{tabular}

During economic downturns, when the unemployment rate was still high and consumption remained low, the respondents' worry about economic uncertainty should not be ignored. Hence greater importance was attached to these macroeconomic variables. Location of the property was claimed by 71 percent each of HOs and NHOs, as either "important" or "very important". The level of importance of location is slightly greater than that of the interest rate, considered by 68 percent of both $\mathrm{HO}$ and NHO groups. This creates an impression that nearly all respondents were aware of the importance of these rational fundamentals.

We learn that there is indirect evidence on the role of psychology in house price cycles. The survey results suggest that the effect of herd behavior of housing consumers seemed to be diminished in the bust period. Yet it still plays a part in housing decisions. Although the "Queue" factor is the least important, about
16 percent and 18 percent of the $\mathrm{HO}$ and $\mathrm{HNO}$ groups, respectively, still viewed it as "important" or "very important". On average, only about one percent of the respondents did not know the importance of rational fundamentals. In sharp contrast, a full 73 percent of HOs and 70 percent of NHOs did not know/decide whether they would buy a property or not, as observed in Table 5. All this suggests that real estate fundamentals would be seriously considered in home purchase, although such elements might not be sufficient to constitute a housing decision.

Another striking feature of the answers is that the "unimportance" of psychology of the market, the "queue" factor, was mentioned by more than 70 percent of the respondents. This indicates that most respondents in the staggering market did not attribute market stiffness to mob psychology. This sketches a very different picture of irrational behavior of people waiting in lines to buy houses in the boom period. 


\section{Forecast of Price Movements}

Overall, 22 percent of respondents thought that property prices had declined, while 78 percent guessed a rise, in the previous three months. When asked about price prediction, only 14 percent cited a decrease, the remaining expected a rise, in the upcoming three months (Table 8).

Most respondents were optimistic about the future market outlook. More HOs expected a rise in housing prices in the upcoming three months than citing a rise in the past three months. Table 9 shows that a bit less than half (45 percent) of HOs thought that the price of their residential units had risen in the previ- ous three months but 52 percent expected a rise in three months' time. Only two percent of HOs expected a decrease in the short term. At the same time, less HOs forecasted a fall in three months' time than citing a fall in previous three months. One plausible explanation for the positive outlook is the increasing confidence among the HOs. This favorable phenomenon also applies to the NHO group, though they were less optimistic. Thirty-five percent of NHOs (less than 52 percent of HOs) expected a price increase in three months against the 23 percent (less than 45 percent of $\mathrm{HOs}$ ) of those who cited an increase in the previous three months.

Table 8. Expected Price Changes in Percentage, by Period (Overall)

\begin{tabular}{|c|c|c|c|c|}
\hline \multirow{2}{*}{$\%$ Change } & \multicolumn{2}{|c|}{ Previous Three Months } & \multicolumn{2}{|c|}{ Forthcoming Three Months } \\
\hline & $\mathbf{N}$ & $\%$ & $\mathbf{N}$ & $\%$ \\
\hline-30 & 1 & 0.7 & 0 & 0 \\
\hline-20 & 2 & 1.3 & 0 & 0 \\
\hline-15 & 1 & 0.7 & 0 & 0 \\
\hline-10 & 10 & 6.7 & 3 & 2.1 \\
\hline-8 & 2 & 1.3 & 2 & 1.4 \\
\hline-6 & 3 & 2.0 & 0 & 0 \\
\hline-5 & 6 & 4.0 & 10 & 6.8 \\
\hline-4 & 5 & 3.3 & 1 & 0.7 \\
\hline-3 & 1 & 0.7 & 1 & 0.7 \\
\hline-2 & 2 & 1.3 & 3 & 2.1 \\
\hline 0.5 & 1 & 0.7 & 0 & 0 \\
\hline 1 & 4 & 2.7 & 12 & 8.2 \\
\hline 2 & 6 & 4.0 & 25 & 17.1 \\
\hline 3 & 17 & 11.3 & 17 & 11.6 \\
\hline 3.5 & 1 & 0.7 & 1 & 0.7 \\
\hline 4 & 6 & 4.0 & 9 & 6.1 \\
\hline 5 & 26 & 17.3 & 20 & 13.7 \\
\hline 6 & 10 & 6.7 & 6 & 4.1 \\
\hline 7 & 0 & 0 & 3 & 2.1 \\
\hline 8 & 10 & 6.7 & 6 & 4.1 \\
\hline 9 & 2 & 1.3 & 3 & 2.1 \\
\hline 10 & 21 & 14.0 & 11 & 7.5 \\
\hline 11 & 0 & 0 & 1 & 0.7 \\
\hline 12 & 0 & 0 & 4 & 2.7 \\
\hline 15 & 9 & 6.0 & 3 & 2.1 \\
\hline 20 & 1 & 0.7 & 3 & 2.1 \\
\hline NK & 3 & 2.0 & 2 & 1.3 \\
\hline Total & 150 & 100 & 146 & 100 \\
\hline
\end{tabular}


Table 9. Forecast of Housing Prices

\begin{tabular}{lllllllll}
\hline Price Changes & \multicolumn{2}{l}{ Previous 3 months } & \multicolumn{7}{l}{ In 3 months time } \\
\cline { 2 - 9 } & $\mathrm{A} 1 \& \mathrm{~A} 2$ & & $\mathrm{~B} 1$ \& 2 & $\mathrm{~A} 1$ \&A2 & $\mathrm{B} 1$ \& 2 \\
\cline { 2 - 9 } & $\mathrm{N}$ & $\%$ & $\mathrm{~N}$ & $\%$ & $\mathrm{~N}$ & $\%$ & $\mathrm{~N}$ & $\%$ \\
\hline Increase & 72 & 44.7 & 42 & 23.3 & 72 & 51.8 & 54 & 34.8 \\
Decrease & 17 & 10.6 & 21 & 11.7 & 3 & 2.2 & 17 & 10.9 \\
Stay the same & 39 & 24.2 & 65 & 34.4 & 40 & 28.7 & 40 & 25.8 \\
Don't know & 33 & 20.5 & 55 & 30.6 & 24 & 17.3 & 44 & 28.5 \\
\hline Total & 161 & 100 & 180 & 100 & 139 & 100 & 155 & 100 \\
\hline
\end{tabular}

Two important observations can be made from the aforesaid results in this section. First, respondents, in particular HOs, seemed to react positively to price movements (Table 9). Second, the magnitude of expected price increases in the short term is greater than the observed price increase in the immediate past (Table 4).

The cross-tabulation analysis in Table 10 below also shows that, overall, 76 percent of respondents thought that housing price had increased in the past three months, at the same time, they expected that prices would continue to rise in the next three months; 77 percent in one year; and 50 percent in three years. Only 16 percent, 14 percent and 8 percent, observing an increase in previous three months, expected prices would remain static

Table 10. Cross-Tabulation of Price Expectations in Forthcoming 3 Months \& Previous 3 Months

\begin{tabular}{|c|c|c|c|c|c|}
\hline \multirow[t]{2}{*}{ Attributes } & & \multicolumn{4}{|c|}{ Expected price increase in 3 months } \\
\hline & & Rise & Stay same & Don't know & Total \\
\hline Price change & Increase & $66(75.9 \%)$ & $14(16.1 \%)$ & $7(8.0 \%)$ & $87(100 \%)$ \\
\hline in previous & Decrease & $13(56.5)$ & $7(30.4 \%)$ & $3(13.1 \%)$ & $23(100 \%)$ \\
\hline \multirow[t]{3}{*}{3 months } & Stay the same & $32(50.0 \%)$ & $19(29.7 \%)$ & $13(20.3 \%)$ & $64(100 \%)$ \\
\hline & DK & $15(27.3 \%)$ & $13(23.6 \%)$ & $27(49.1 \%)$ & $55(100 \%)$ \\
\hline & Total & $126(55.0 \%)$ & $53(23.2 \%)$ & $50(21.8 \%)$ & $229(100 \%)$ \\
\hline \multirow[t]{2}{*}{ Attributes } & & \multicolumn{4}{|c|}{ Expected price increase in 1 year } \\
\hline & & Rise & Stay same & Don't know & Total \\
\hline Price change & Increase & $67(77.0 \%)$ & $12(13.8 \%)$ & $8(9.2 \%)$ & $87(100 \%)$ \\
\hline in previous & Decrease & $9(39.1 \%)$ & $6(26.1 \%)$ & $8(34.8 \%)$ & $23(100 \%)$ \\
\hline \multirow[t]{3}{*}{3 months } & Stay the same & $37(57.8 \%)$ & $10(15.6 \%)$ & $17(26.6 \%)$ & $64(100 \%)$ \\
\hline & DK & $22(40.0 \%)$ & $6(10.9 \%)$ & $27(49.1 \%)$ & $55(100 \%)$ \\
\hline & Total & $135(59.0 \%)$ & $34(14.8 \%)$ & $60(26.2 \%)$ & $229(100 \%)$ \\
\hline \multirow[t]{2}{*}{ Attributes } & & \multicolumn{4}{|c|}{ Expected price increase in 3 years } \\
\hline & & Rise & Stay same & Don't know & Total \\
\hline Price change & Increase & $43(49.4 \%)$ & $7(8.0 \%)$ & $37(42.5 \%)$ & $87(100 \%)$ \\
\hline in previous & Decrease & $7(30.4 \%)$ & $5(21.7 \%)$ & $11(47.8 \%)$ & $23(100 \%)$ \\
\hline \multirow[t]{3}{*}{3 months } & Stay the same & $31(48.4 \%)$ & $4(6.3 \%)$ & $29(45.3 \%)$ & $64(100 \%)$ \\
\hline & DK & $8(14.5 \%)$ & $5(9.1 \%)$ & $42(76.4 \%)$ & $55(100 \%)$ \\
\hline & Total & $89(38.9 \%)$ & $21(9.2 \%)$ & $119(52.0 \%)$ & $229(100 \%)$ \\
\hline
\end{tabular}


in the same corresponding three horizons, respectively. In overall terms, 57 percent, 39 percent and 30 percent of the respondents, suggesting a fall in the past three months, had changed their forecast to a price rise in the 3month, 1-year and 3-year horizons. This indicates that respondents changed from the perception of a pessimistic outlook hitherto to a positive one in the immediate future. This change is significant, but not enormous.

Apparently, the formation of respondents' price expectations, as perceived by HOs and NHOs, was based on the rising trend in housing prices in the immediate past. More precisely, the observed favorable market situation (reflected by the moderate price increase statistics compiled by the Rating and Valuation Department, the Government of the Hong Kong Special Administrative Region) was expected to continue in the immediate future. This leads to a strong impression that there appears a substantial co-movement between short-term positive price expectations and the immediate past trend of rising prices. Further analysis shows that the Spearman correlation coefficient is $0.412(\mathrm{~N}=229)$, significant at the 95 percent confidence level. In short, the statistical relation between expectations of a price increase, in percentage terms, in three months and actual changes in prices over the previous three months in the mind of the respondents is moderately strong (Table 11).

The results seem to reject rational expectations and strong market efficiency, yet consistent with the literature (see, for example, Hamilton and Schwab, 1985; Clayton, 1996; Tse and Webb, 2001). Much of the inflation expectations literature suggests that individuals tend to refer to past experience to estimate future inflation outcome, generating adaptive expectations. Assuming the vast majority of respondents are right most of the time, especially at market bottoms, it is immediately apparent that hope-led expectations increase the likelihood of a persistent price increase.

Other than the moderately strong association between the current capital gains and expected capital gains, the data shows a very

Table 11. Spearman Correlation Matrix

\begin{tabular}{lll}
\hline & & Expected price increase (\%) in 3 months \\
\hline Price changes in previous 3 months & Spearman correlation & 0.412 \\
& Sig. (2-tailed) & 0.000 \\
& $\mathrm{~N}$ & 229 \\
\hline Sex & Spearman correlation & 0.108 \\
& Sig. (2-tailed) & 0.102 \\
& $\mathrm{~N}$ & 229 \\
\hline Good / bad time to buy & Spearman correlation & 0.163 \\
& Sig. (2-tailed) & 0.003 \\
& $\mathrm{~N}$ & 341 \\
\hline Family income & Spearman correlation & -0.269 \\
& Sig. (2-tailed) & 0.000 \\
& $\mathrm{~N}$ & 199 \\
\hline Education level & Spearman correlation & -0.273 \\
& Sig. (2-tailed) & 0.000 \\
& $\mathrm{~N}$ & 226 \\
\hline Age & Spearman correlation & 0.021 \\
& Sig. (2-tailed) & 0.756 \\
& $\mathrm{~N}$ & 220 \\
\hline
\end{tabular}


Table 12. Best Linear Predictors of Price Expectations, by Demographics

\begin{tabular}{lllllll}
\hline $\begin{array}{l}\text { Predictor } \\
\text { variables }\end{array}$ & \multicolumn{2}{l}{$\begin{array}{l}\text { Price expectations (rise, same, don't know) in 3 } \\
\text { months }\end{array}$} & \multicolumn{2}{l}{ Expected price increase (\%) in 3 months } \\
\cline { 2 - 7 } & Coeff. & Std. error & $\mathbf{t}$ & Coeff. & Std. error & $\mathbf{t}$ \\
\hline Sex & 0.078 & 0.109 & 1.130 & 0.153 & 0.874 & 1.506 \\
Age & -0.050 & 0.046 & -0.715 & -0.072 & 0.349 & -0.705 \\
Education & -0.208 & 0.106 & -2.766 & 0.088 & 0.746 & 0.849 \\
Income & -0.202 & 0.037 & -2.699 & -0.028 & 0.286 & -0.273 \\
\hline Intercepts & 2.652 & & & 2.842 & & \\
R sq. & 0.130 & & & 0.039 & & \\
DW & 2.021 & & 2.079 & & \\
$\mathbf{N}$ & 106 & & & 106 & & \\
\hline
\end{tabular}

weak relation, in general, between expected housing price increase in percentage and other predictors of "timing to buy" (the Spearman coefficient is 0.163$)$, "age" (0.021), "sex" (0.108), "family income" (-0.269), and "education" ($0.273)$. The explanatory power of these variables for the price prediction, such as "rise", "remain the same" or "don't know" and for the percentage price increase, both in three months, is also very low (Table 12). The $R$ squared for the forecast is $0.130(\mathrm{DW}=2.021)$; and the percentage price increase, 0.039 (DW $=2.079$ ), both with $\mathrm{N}=106$. This leads us to believe that short term price expectations, based on past trends, can provide an individual a better understanding of the market performance. Hence BRE Indices developed from price expectations might be useful in price prediction.

\section{CONCLUSIONS}

The findings of the first survey are simple, yet it is believed that the predicting power of the Index can be powerful. The results, suggest, first of all, that confidence of housing actors in Hong Kong has started improving since the property crash in 1997. The "overall" BRE Index stood at 564 in the fourth quarter of 2003. It is observed that the market was driven largely by hope-led expectations. Housing prices are expected to continuously rise by a small margin in the short term. Statistically, the expected price increase by homeowners is not significantly different from the non-owners. Second, participants' expectations of rising real estate prices are associated with the immediate past price movements; and their relation is moderately strong. Further, there is a co-movement between past capital gains and forecast capital gains. Assuming market participants are accurate most of the time in believing that appreciation in the past implies capital gains in the future, it is immediately apparent that such expectations increase the likelihood of sustaining housing prices increase. If the households formed their expectations similarly in other periods, there would be similar "positive hit" results, rendering the Index more convincing. The recent price boom in the residential sector, particularly the luxury flats after the first survey was conducted, confirms that what the respondents originally expected is fulfilled in general. While the evidence is circumstantial we can only offer conjectures that people form their expectations on the basis of previous price patterns. Recognizing that economic conditions are important in housing decisions, people may continue to use the adaptive approach to make optimal forecast. But during times when "bubbles" emerge (a self-fulfilling prophecy), changes in expectations and emotional decisions play a significant role in market irrationality. In that case, micro fundamentals offer only a partial solution. Developmental trends in people's expec- 
tations and confidence to be developed from future longitudinal survey data will help shed light on market performance.

It is known that the fundamental value of a real property is the expected (not past) stream of rental income (either market rent or imputed rent), coupled with capital gains. Confidence on the future market performance appears to have strong explanatory power regarding the movement of property prices. Establishing BRE Indices involves the investigation of the complexity of people's views about the future outlook in the property sector. A forward-looking approach is able to offer some practical guidance about investor confidence in the future. Property prices are determined by supply and demand, and there are a host of factors that affect these variables. Consumers' confidence towards the property market is only one of these market forces, along with economic, political, social, technological, international as well as psychological factors, to offer assistance in conjectures regarding the market dynamics. Sometimes a set of factors is more important, albeit at other times that particular set is relatively insignificant. With this in mind, cross-sectional confidence indices can only play a supportive role in understanding the market performance. However, with longitudinal data, we should be able to establish scientifically the relationship between expectations and housing price formation.

\section{Acknowledgements:}

The authors are grateful to Francis K.W. Wong, William Seabrooke and Y.H. Chiang for their helpful comments. We are very grateful to M.E. DeGolyer, J.H. Leigh for providing technical advice, and to P.K. Cheung for excellent research assistance. None of these people is responsible for any errors herein. The views expressed in this paper are those of the authors, and not necessarily those of the Research Centre for Construction and Real Estate Economics, Department of Building and Real Estate, The Hong Kong Polytechnic University, which funded this study.

\section{REFERENCES}

Case, K. E. and Shiller, R. J. (1990) Forecasting prices and excess returns in the housing market. Journal of American Real Estate and Urban Economics Association, 18, p. 253-73.

Case, K. E. and Shiller, R. J. (1989) The efficiency of the market for single-family homes. The American Economic Review, 79(1), p. 125-37.

Clayton, J. (1996) Rational expectations, market fundamentals and housing price volatility. Real Estate Economics, 24(4), p. 441-70.

Diamond, D. (1980) Taxes, inflation, speculation and the cost of homeownership. AREUEA Journal, 8, p. 281-98.

Hamilton, B. W. and Schwab, R. (1985) Expected appreciation in urban housing markets. Journal of Urban Economics, 18, p. 103-18.

Harris, J. C. (1989) The effect of real rates of interest on housing prices. Journal of Real Estate Finance and Economics, 2, p. 47-60.

Mankiw, N. and Weil, D. N. (1989) The baby boom, the baby bust and the housing market. $R e$ gional Science and Urban Economics, 19, p. 235-58.

McDonald, J. F. (1985) Expectations and urban housing prices. Urban Studies, 22, p. 543-49.

Muth, J. F. (1961) Rational expectations and the theory of price movements. Econometrica, 29, p. $315-35$.

Ott, S. H., Riddiough, T. J., Yi, H. C., and Yoshida, J. (2000) On demand: Cross-Country Evidence from Commercial Real Estate Markets. Processed, 2000.

Phillips, R. S. (1985) The Relationship between the Residential Rents and House Values explaining Inter-temporal and Cross-sectional Variation, 1974-1979. US Department of Housing and Urban Development.

Stiglitz, J. E. (1990) Symposium on bubble. Journal of Economic Perspectives, 4(2), p. 13-18.

Tse, R. Y. C. and Webb, J. R. (2001) Public vs private real estate in Hong Kong using adaptive expectations. Journal of Real Estate Portfolio Management, 7(2), p. 143-49.

Turnovsky, S. J. (1970) Empirical evidence on the formation of price expectations. Journal of American Statistical Association, 65(332), p. 1441-54. 